\title{
Assessment of copy number variation in genes related to drug resistance in Plasmodium vivax and Plasmodium falciparum isolates from the Brazilian Amazon and a systematic review of the literature
}

Gabriel Luíz Costa' ', Lara Cotta Amaral', Cor Jesus Fernandes Fontes², Luzia Helena Carvalho', Cristiana Ferreira Alves de Brito ${ }^{1}$ and Taís Nóbrega de Sousa ${ }^{1 *}$

\begin{abstract}
Background: Parasite resistance to anti-malarials represents a great obstacle for malaria elimination. The majority of studies have investigated the association between single-nucleotide polymorphisms (SNPs) and drug resistance; however, it is becoming clear that the copy number variation (CNV) is also associated with this parasite phenotype. To provide a baseline for molecular surveillance of anti-malarial drug resistance in the Brazilian Amazon, the present study characterized the genetic profile of both markers in the most common genes associated with drug resistance in Plasmodium falciparum and Plasmodium vivax isolates. Additionally, these data were compared to data published elsewhere applying a systematic review of the literature published over a 20-year time period.
\end{abstract}

Methods: The genomic DNA of 67 patients infected by $P$. falciparum and P. vivax from three Brazilian States was obtained between 2002 and 2012. CNV in P. falciparum multidrug resistance gene-1 (pfmdr1), GTP cyclohydrolase 1 (pfgch 1) and P. vivax multidrug resistance gene-1 (pvmdr1) were assessed by real-time PCR assays. SNPs in the pfmdr1 and pfcrt genes were assessed by PCR-RFLP. A literature search for studies that analysed CNP in the same genes of $P$. falciparum and P. vivax was conducted between May 2014 and March 2017 across four databases.

Results: All analysed samples of P. falciparum carried only one copy of pfmdr1 or pfgch1. Although the pfcrt K76T polymorphism, a determinant of CQ resistance, was present in all samples genotyped, the pfmdr1 N86Y was absent. For P. vivax isolates, an amplification rate of $20 \%$ was found for the pvmdr 1 gene. The results of the study are in agreement with the low amplification rates for pfmdr1 gene evidenced in the Americas and Africa, while higher rates have been described in Southeast Asia. For P. vivax, very low rates of amplification for pvmdr 1 have been described worldwide, with exceptions in French Guiana, Cambodia, Thailand and Brazil.

Conclusions: The present study was the first to evaluate gch1 CNV in P. falciparum isolates from Brazil, showing an absence of amplification of this gene more than 20 years after the withdrawal of the Brazilian antifolates therapeutic scheme. Furthermore, the rate of pvmdr1 amplification was significantly higher than that previously reported for isolates circulating in Northern Brazil.

\footnotetext{
*Correspondence: tais@cpqrr.fiocruz.br

${ }^{1}$ Molecular Biology and Malaria Immunology Research Group, Centro

de Pesquisas René Rachou, Fundação Oswaldo Cruz (FIOCRUZ), Belo

Horizonte, Minas Gerais, Brazil

Full list of author information is available at the end of the article
} 
Keywords: Malaria, Plasmodium falciparum, Plasmodium vivax, Drug resistance, Copy number variation, Single nucleotide polymorphism, Systematic review

\section{Background}

Malaria is an endemic disease and 3.2 billion people are exposed to its transmission in 95 countries and territories around the world. This disease is caused by five species of Plasmodium, with Plasmodium vivax having a wider geographic distribution and Plasmodium falciparum responsible for the most severe malaria cases associated with high mortality rates [1]. According to the latest estimates, in 2015, approximately 143,000 cases were registered in the Brazilian Amazon region, with $87 \%$ of cases due to $P$. vivax [2].

One of the greatest challenges of malaria control is the parasite's resistance to anti-malarials, defined as the ability of a parasite to survive and/or multiply in the presence of a drug [3]. In Brazil, the first case of drug resistance in P. falciparum malaria was reported in the early nineteenth century, to quinine $(\mathrm{QN})$, the first drug used for malaria treatment [4]. It was only in the 1960s that an increased number of cases of $P$. falciparum chloroquine (CQ) resistance began to be reported in the country, concomitant with other countries from South America and Asia [5, 6]. In the 1970s, the Brazilian government adopted sulfadoxine-pyrimethamine (SP) as the first-line treatment; however, in the late 1980s, the rate of SP resistance was close to $90 \%$ [7]. From the late 1980 s to 2000 , Brazil applied various therapeutic schemes, and in 2007 the artemisininbased combination therapy (ACT) was adopted according to the WHO recommendations to treat uncomplicated P. falciparum malaria [6]. Despite the reports of low susceptibility in Asia [8-11] and South America [12], ACT remains effective in Brazil [13]. Concerning $P$. vivax malaria, even though this species has been the most prevalent in Brazil for decades, it is only in the last few years that this species has developed low levels of drug resistance [14-17] and cases of severe malaria [18, 19] have been reported in the Amazon region. Thus, CQ plus primaquine (PQ) is still effective in this area [20].

Anti-malarial resistance studies and surveillance can be conducted using in vitro parasite culture, animal models, in vivo methods and molecular genotyping [21]. The latter aims to identify and monitor genetic polymorphisms related to parasite resistance. Such markers are mainly SNPs, which are characterized by the substitution of a single nucleotide, and CNVs. CNV refers to an increase or decrease in the copy number of a gene in the genome; CNVs are extensively found in humans, mice, Drosophila and other eukaryotes [22, 23].
The importance of copy number variation in the Plasmodium genome was noticed when an elevated copy number of the mdr1 (multidrug resistance gene-1) gene was reported and associated with multidrug resistance in P. falciparum isolates in Asia in the late 1980s [24]. The $p f m d r 1$ gene encodes a protein localized in the parasite digestive vacuole named P-glycoprotein homolog 1 (P-gh1), and many studies have shown a strong association between $p f m d r 1$ and the multidrug resistance phenotype, such as to mefloquine (MQ), QN and halofantrine (HF) [25-27]. Another gene related to SP resistance in $P$. falciparum and characterized by copy number variation is gch1 (GTP cyclohydrolase 1), a gene encoding the enzyme GTP cyclohydrolase 1 that catalyzes the first step in the folate biosynthesis pathway [28-30]. Regarding CNV in P. vivax, the amplification of pvmdr1, orthologous to $p f m d r 1$, seems to also be related to drug resistance [31,32]. Due to the challenges of conducting in vitro studies in $P$. vivax, the understanding concerning the resistance to anti-malarials for this species is less comprehensive.

Despite the increased importance of $\mathrm{CNV}$ over the last decades, SNPs are the first polymorphisms associated with drug resistance in Plasmodium. In P. falciparum some SNPs have a major role in the drug resistance phenotype, e.g., K76T polymorphism in the $p f c r t$ (P. falciparum chloroquine-resistant transporter) gene and N86Y, Y184F, S1034C, N1042D, D1246Y in the pfmdr1 gene $[33,34]$, while only the mutation Y976F in the pvmdr1 gene was related to clinical resistance to CQ in P. vivax in Southeast Asia and Papua New Guinea [35-37].

Many questions remain about the genetic basis of resistance in $P$. falciparum and $P$. vivax. A majority of studies has investigated the association between SNPs in the genome of Plasmodium and resistance to anti-malarials. However, it has become clear that the copy number variation is also associated with this parasite phenotype. The present study characterized the genetic profile of $\mathrm{CNV}$ in genes associated with drug resistance in $P$. falciparum and $P$. vivax isolates to provide a baseline for molecular surveillance of anti-malarial drug resistance in the Brazilian Amazon region. Moreover, SNPs in the same $P$. falciparum genes were assayed and correlated to the genetic profile observed for CNV. Finally, the genetic variability described in Brazilian isolates was compared to data published elsewhere applying a systematic review of the literature. 


\section{Methods}

\section{Subjects and sample collection}

Sixty-seven patients infected by $P$. vivax or $P$. falciparum from three Brazilian states (31 from Mato Grosso, 26 from Rondônia and 10 from Amapá) were included in this study (Table 1). Epidemiological data indicate that malaria transmission in these areas is generally hypo- to meso-endemic [13]. In Rondônia and Amapá, the individuals were locally infected. However, individuals from Mato Grosso may have acquired the infection in other localities of the Amazon region because there is no transmission in the municipality of blood collection. The eligibility criteria included (i) patients with symptomatic $P$. vivax or $P$. falciparum single infection with any parasitaemia by microscopic examination; (ii) the absence of severe complications of malaria; and, (iii) if the patient was female, the absence of pregnancy. The confirmation of Plasmodium spp. infection by microscopy was based on Giemsa-stained thick blood smears evaluated by well-trained microscopists in accordance with the malaria diagnosis guidelines of the Brazilian Ministry of Health. DNA samples were extracted from peripheral blood collected in EDTA-containing tubes for parasite genomic analysis using QIAamp DNA kit (QIAGEN, Chatsworth, CA, USA). Samples were collected between August 2002 and May 2012. Molecular detection and identification of Plasmodium species were confirmed later by nested PCR amplification of the $18 \mathrm{~S}$ rRNA gene in the laboratory to exclude mixed malaria infections [38].

\section{Copy number estimation of Plasmodium spp. genes}

The copy number variation of Plasmodium genes was determined by quantitative real-time PCR (qPCR) using specific hydrolysis probes and oligonucleotide primers for each gene. Probes and primers previously described were used for amplification of pfmdr1 [27], pfgch1 [28] and pvmdr1 [31]. Amplification reactions were performed in a total volume of $10 \mu \mathrm{L}$ in the presence of $5 \mu \mathrm{L}$ of Taqman ${ }^{\circledR}$ Universal PCR Master Mix 2× (Applied Biosystems, AB, Foster City, CA, USA), $1 \mu \mathrm{L}$ DNA ( $\approx 100 \mathrm{ng} / \mu \mathrm{L}), 900 \mathrm{nM}$ (pfmdr1, pfgch1 and pvmdr1) or $300 \mathrm{nM}$ (pftubulin and pvtubulin) of forward primer, $900 \mathrm{nM}$ of reverse primer (for all genes), and $200 \mathrm{nM}$ (pfmdr1, pfgch1 and pvmdr1) or $250 \mathrm{nM}$ (pftubulin and pvtubulin) of the probe. The cycling parameters for PCR were as follows: initial denaturation at $95^{\circ} \mathrm{C}$ for $10 \mathrm{~min}, 40$ cycles of $15 \mathrm{~s}$ at $95^{\circ} \mathrm{C}$ and $1 \mathrm{~min}$ at $60{ }^{\circ} \mathrm{C}$. The PCR was performed in triplicate in the Applied Biosystems Viia7 real-time PCR system (AB) in 384 plates. The single-copy $\beta$-tubulin gene was used as a reference gene (normalizer) [27, 31], and a field sample with a single copy of the target gene was used as a calibrator. The $\Delta \Delta \mathrm{Ct}$ method was used to estimate the copy number of $p f m d r 1$ and $p v m d r 1$ genes relative to a standard calibrator sample. For the pfgch1 gene, a calibration curve was used with plasmids containing the pfgch1 insert. The samples were considered to have a copy number equal to 1 when the value of the relative quantification was between 0.5 and 1.5 , and values with a minimum relative quantification $>1.5$ were defined as amplified. Only samples with a cycle threshold $<32$ and a Ct standard deviation $<0.3$ were considered in the analysis. Each experiment was performed in triplicate, and gene amplification was determined by at least two independent experiments. The accuracy of the qPCR assay was determined from at least three independent experiments, each performed in triplicate, of $19 \%$ of the total samples assayed and for the reference laboratory isolate W2mef (2 copies for $p f m d r 1$ and 1 copy for $p f g c h 1$ ) (Additional file 1 ).

\section{Detection of single nucleotide polymorphisms in the pfcrt and pfmdr 1 genes}

PCR followed by restriction fragment length polymorphism analysis (RFLP) was performed to identify SNPs

Table 1 Description of samples included in this study by period of collection, gender, age and parasitemia

\begin{tabular}{|c|c|c|c|c|}
\hline Region $(\mathrm{N})^{\mathbf{b}}$ & Period & Gender (male, \%) & $\begin{array}{l}\text { Median age, } \\
\text { years (IQR') }\end{array}$ & $\begin{array}{l}\text { Parasitemia, geometric } \\
\text { mean (range) }\end{array}$ \\
\hline \multicolumn{5}{|c|}{ Patients infected by P. falciparum ${ }^{a}$} \\
\hline Amapá (10) & 2004-2005 & 60 & $35(27-46)$ & $1306(605-2500)$ \\
\hline Rondônia (4) & 2008 & 75 & $42(32-52)$ & $5004(1520-24,650)$ \\
\hline Mato Grosso (18) & 2002-2012 & 83 & $36(26-43)$ & $1505(62-56,660)$ \\
\hline \multicolumn{5}{|c|}{ Patients infected by P. vivax ${ }^{a}$} \\
\hline Mato Grosso (13) & 2005-2012 & 92 & $35(17-49)$ & $4816(992-17,500)$ \\
\hline Rondônia (22) & 2008 & 73 & $41(23-50)$ & $1840(95-10,770)$ \\
\hline \multicolumn{5}{|c|}{$\begin{array}{l}\text { First line treatment for uncomplicated } P \text {. falciparum malaria during sample collection: } Q N+\text { doxycycline }+ \text { PQ (2001-2007) and ACT (after 2007). Treatment scheme } \\
\text { for P. vivax therapy: CQ + PQ [6] }\end{array}$} \\
\hline \multicolumn{5}{|c|}{ b State of sample collection and number of isolates analysed } \\
\hline \multicolumn{5}{|l|}{ c Interquartile range } \\
\hline \multicolumn{5}{|l|}{ d Parasites $/ \mu \mathrm{L}$} \\
\hline
\end{tabular}


at codons 76 of $p f c r t$ and 86 of $p f m d r 1$, according to Durand et al. [39] and Lopes et al. [40], respectively. The amplicons were submitted to enzyme digestion with ApoI (New England BioLabs, Ipswich, MA, USA) for $2 \mathrm{~h}$ at $50{ }^{\circ} \mathrm{C}$. Then, the enzyme was inactivated by exposure to a temperature of $80{ }^{\circ} \mathrm{C}$ for $20 \mathrm{~min}$ at and the fragments were visualized on a silver-stained $12 \%$ polyacrylamide gel.

\section{Systematic review}

A literature search was conducted between May 2014 and March 2017. An advanced search was made using key words (Plasmodium, copy number, resistance, gene, copy number resistance and gene copy). These key words were identified in the title, abstract and text, according the search algorithm of each database. Manual exclusion criteria included: studies with other Plasmodium species than $P$. falciparum and $P$. vivax; studies with laboratory strains grown in vitro; other systematic reviews; and studies with genes related to anti-malarial resistance other than $p f m d r 1, p f g c h 1$ and $p v m d r 1$. All duplicate articles and review articles were excluded; the clinical studies were included in this systematic review. The title, abstract and methods section of all 309 articles (Additional file 2) were scanned to identify the studies according to the inclusion criteria. From the eligible studies the following data were extracted: author, year of sample collection (when available), country where the study was performed, sample number and the frequency of CNV in parasite population by gene assayed.

\section{Results and discussion}

\section{Copy number estimation of $m d r 1$ and gch 1 of Plasmodium} falciparum

31 samples of patients infected by $P$. falciparum were evaluated for copy number variation in the $p f m d r 1$ gene and 25 samples for $p f g c h 1$. Parasite isolates were sampled in three regions of Brazil (the Mato Grosso, Rondônia and Amapá states) over a period of 10 years (Table 1). For both genes analysed in this study all $P$. falciparum isolates carried only one copy of the gene (Fig. 1; Additional file 3A, B).

Polymorphisms in $p f m d r 1$ are related to resistance to several anti-malarials, including $\mathrm{CQ}, \mathrm{MQ}, \mathrm{QN}$ and $\mathrm{HF}$ [41]. An increase in the copy number of this gene is the most important determinant of resistance to MQ and to reduced artesunate sensitivity in vitro [26, 27, 42]. In Brazil, P. falciparum resistance to anti-malarials has been reported since $1910(\mathrm{QN}-1910 ; \mathrm{CQ}-1960 \mathrm{~s}$; SP-1980s; amodiaquine and MQ-1990s) [6]. Another study also assessed the presence of $\mathrm{CNV}$ in the $p f m d r 1$ gene from samples collected over four decades in Brazil (from 1984 to 2011), in which patients were treated with QN plus

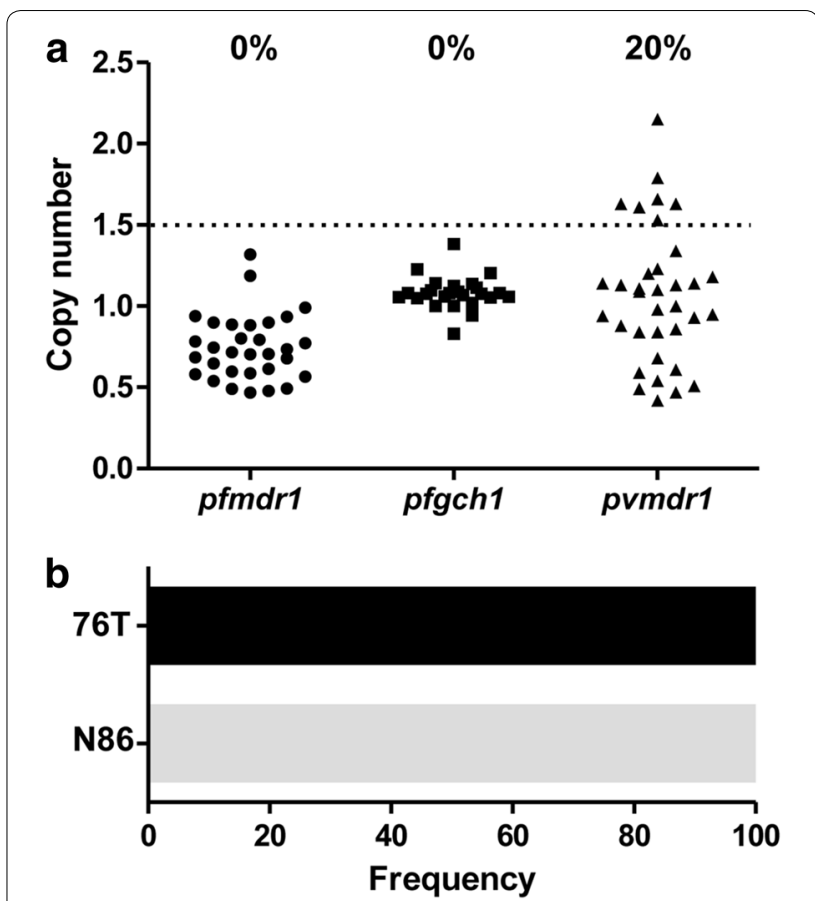

Fig. 1 Polymorphism analysis in genes of P. falciparum and P. vivax isolates from different Brazilian Amazon regions. a Copy number variation in genes of $P$. falciparum and $P$. vivax. Only samples with relative quantification above 1.5 were considered amplified. Amplification rates for each gene are indicated in the graph. $\mathbf{b}$ Frequency of the 76T mutant allele in pfcrt and N86 wild-type allele in pfmdr1. The frequencies of wild-type and mutated alleles are shown in black and gray, respectively

tetracycline, MQ or ACT [43]. During that period, the rate of $p f m d r 1$ amplification reached $42 \%$. Particularly, the usage of drugs such as MQ, which is related to selection of resistant parasites with pfmdr1 amplification, could be an explanation for the observed high rates of amplification. A noticeable difference between the present study and that by Inoue et al. is the region and the period of sample collection (2000s herein), which could lead to the observed differences in genetic diversity. Accordingly, geographical foci of P. falciparum with distinct population structures have been described in the Brazilian Amazon region [44]. However, as data from the previous study have not been shown by region, differences in CNV distribution due to the location of the infection could not be assessed here. Alternatively, cases of a decline in resistant isolates by the withdrawal of drug pressure could have occurred as previously reported in Africa $[45,46]$. The genome of $P$. falciparum is known to be plastic [47], which means that the parasite can experience rapid and extensive variation in response to changes in its environment; this is also known as phenotypic plasticity [48]. In a short timescale, this phenotypic 
plasticity can modify or produce new phenotypes. Thus, this phenomenon enables parasites to maximize fitness by mechanisms such as differential gene expression [49]. An example was shown by Preechapornkul et al. where strains containing a single copy of the gene preferentially survived in the absence of MQ compared to those who had multiple copies [25]. Parasites that had fewer copies had a greater survival rate due to this energy demand generated by P-gh1. This protein acts as an efflux pump that transports substrates against a concentration gradient with ATP hydrolysis [50]. In Brazil, MQ was officially introduced in 1987 for the treatment of CQ- and SP-resistant P. falciparum, and few years later, in 2001, MQ was substituted with the combination of QN plus doxycycline, followed by primaquine $(\mathrm{PQ})$ as a first line therapy [6]. At this time, MQ plus PQ was instituted as a second line drug combination, and only after 2006 did the ACT become adopted in Brazil [6]. Thus, the lower pressure exerted by MQ may have led to selection of parasites bearing no genetic amplification after the first decade of the 2000s.

Plasmodium falciparum resistance to SP is associated with SNPs in two genes in the folate pathway, dihydrofolate reductase (dhfr) and dihydropteroate synthetase (dhps) [51, 52]. However, polymorphisms in these genes may alter their efficiencies. The pfgch 1 gene encodes the first enzyme of this pathway and an increased copy number of this gene may act as a compensatory mechanism since it is associated with a greater number of point mutations in $d h f r$ and dhps [28, 53, 54]. Few studies have evaluated the role of CNV in resistance to SP, particularly in the Americas. The present study was the first to evaluate gch1 CNV in P. falciparum isolates from Brazil. Samples analysed here date from the 2000s, more than twenty years after the withdrawal of SP in the Brazilian therapeutic scheme in the late 1980s. Thus, the absence of amplification of the pfgch1 gene in the Brazilian isolates may be the result of antifolates withdrawal, which could have favored the spread of parasites bearing a single copy of the gene. In fact, the presence of CNV in this gene seems to not be advantageous in the absence of the drug pressure, having impact on parasite growth [53]. Still, since the evolution of antifolate-resistant parasites is multifaceted and complex and the activity of the gch1 gene is linked with other enzymes (e.g., dhps and dhfr), further analysis is required to confirm the significance of gch $1 \mathrm{CNV}$ on the gain in SP resistance.

\section{Analysis of single nucleotide polymorphisms in the crt and $m d r 1$ genes of Plasmodium falciparum}

The samples of $P$. falciparum were assayed for two polymorphisms in pfcrt (K76T) and pfmdr1 genes (N86Y). Twenty-seven samples $(84 \%$ [27/32]) were successfully genotyped (10 from Amapá, 16 from Mato Grosso and 1 from Rondônia) for both genes. For pfcrt gene, all samples carried the polymorphism at codon 76 , while the substitution N86Y in the pfmdr1 gene was absent (Fig. 1). The fixation of the $76 \mathrm{~T}$ allele is in agreement with other studies in Brazil [43, 55, 56], despite the withdrawal of CQ from national treatment guidelines in the mid-1980s [57]. The presence of the $76 \mathrm{Y}$ allele is in accordance with the description of isolates resistant to CQ in the same regions analysed here $[43,55]$. The K76T mutation has been proven essential to $C Q$ resistance, as demonstrated by transfection experiments and it was suggested that this mutation in the pfcrt gene confers resistance to CQ by reducing the amount of drug in the digestive vacuole of the parasite [33, 34, 58, 59].

Field studies have observed a significant association between the $p f c r t$ (76T) and $p f m d r 1$ (86T) alleles, suggesting a joint contribution of these two genes to CQ resistance $[60,61]$. Reinforcing these findings, the study by Veiga et al. using zinc-finger nucleases to genetically modify the $p f m d r 1$ gene confirmed the contribution of the N86Y substitution to CQ and amodiaquine resistance. In contrast, this substitution increased parasite susceptibility to MQ and lumefantrine [62]. Additionally, an association between the $86 \mathrm{Y}$ mutant and reduced susceptibility to artemether was found using in vitro tests [63], although other studies have reported contradictory results with the N86Y substitution associated with increased artemether sensitivity $[45,64,65]$. In samples analysed here, the N86Y substitution was absent, a similar result to that observed by other studies that have also reported low frequency or absence of this substitution in pfmdr1 in Brazil [43, 55, 56]. On the other hand, Inoue et al. reported the emergence of the $86 \mathrm{Y}$ mutant in 25 and $43 \%$ of isolates from Brazil and Guyana, respectively, over the last few decades. These findings led the authors to hypothesize that the increase in prevalence of the $86 \mathrm{Y}$ mutant could be related to the indiscriminate use of ACT in Guyana and the high flow of gold mine workers between Brazil and this neighboring country. Although not analysed here, other polymorphisms (e.g. Y184F, S1034C, N1042D and D1246Y) that influence parasite response to different drugs such as $\mathrm{CQ}, \mathrm{MQ}, \mathrm{QN}, \mathrm{HF}$ and artemisinin $[41,66,67]$ are found with high frequency in South America [43, 55, 68-70]. In this way, it seems that the markers of CQ resistance may differ between South America and other endemic areas. Thus, it is necessary to define better and more reliable polymorphisms to characterize South American samples.

\section{Copy number estimation of mdr 1 of Plasmodium vivax}

To characterize the pattern of copy number variation of $P$. vivax isolates from the Brazilian Amazon region, 
thirty-five samples collected in various time periods and from two different areas (the states of Mato Grosso and Rondônia) were analysed. Overall, an amplification rate of $20 \%(7 / 35)$ was found for the pvmdr1 gene (Fig. 1). In Mato Grosso, six of 13 (46\%) isolates had multiple copies of the pvmdr1 gene (Additional file 3C). Despite being collected in the state of Mato Grosso, the probable locality of infection for these individuals carrying isolates with multiple copies of $p v m d r 1$ included others areas of the Amazon region, including the states of Pará and Rondônia, as well as the neighboring country French Guiana. In addition, the majority of these isolates were collected in the 2010s decade. For 22 samples collected in Rondônia only one (4\%) had multiple copies of the pvmdr1 gene (Additional file 3C). Overall, $p v m d r 1$ copy number variation was not related to parasitaemia (median: 3150 [IQR 2935-12,000 parasites/ $\mu$ ] for individuals carrying isolates with multiple copies vs. 2483 [992-6175 parasites/ $\mu$ ] for samples with one copy of pvmdr1; Mann-Whitney U test, $P=0.201$ ) or age (mean: 32 [SD 14.8 years] for samples with multiple copies vs. 37 [15.1 years] for samples with one copy of pvmdr1; Student's t test, $P=0.469)$. Among samples with multiple copies of $p v m d r 1$, the recurrence of the disease was reported in two individuals from Mato Grosso in a period of 45 days to 3 months after the initial infection.

In Brazil and in several other malaria endemic areas CQ and PQ are still the main drugs used to treat $P$. vivax [71]. However, resistance to CQ has been reported in the Brazilian Amazon [14-17]. Similar to P. falciparum, the copy number variation on $p v m d r 1$ is supposed to be related to drug resistance [31]. In Brazil, only one study described pvmdr1 copy number variation, showing an amplification rate of $0.9 \%$ in isolates from the state of Acre [72]. Furthermore, the authors have not observed any relation between SNPs described in pvmdr1 and CQ resistance. In this study, $p v m d r 1$ amplification was observed in $20 \%$ of patients infected in different areas of Northern Brazil. One individual was declared to have been infected in French Guiana, where a high number of isolates with multiple copies of the pvmdr1 gene has previously been reported [73, 74]. The clinical features of age and parasitaemia, which are important predictors of patient's response to the treatment [27, 75, 76] did not differ between individuals carrying parasites with one or multiple copies of $p v m d r 1$ in the present study. Thus, for the two individuals bearing isolates with multiple copies of the gene who also had episodes of recurrence, there is the possibility of treatment failure due to parasite resistance to anti-malarials. However, as the individuals were not followed up after drug therapy with plasma drug level and parasitaemia measurements, the authors could not exclude the possibility of inadequate drug absorption.
Additionally, the authors could not exclude the possibility of recurrence due to CQ or PQ-impaired metabolism by variants of cytochrome P450 isoenzymes [77], as the genes that encode the enzymes were not assayed here. On the other hand, a new infection seems to be unlikely since these individuals reside in an area without active transmission of malaria and did not travel to other endemic areas in the Brazilian Amazon after their initial infections.

As previously suggested for other geographical locations, $p v m d r 1$ amplification could be associated with MQ pressure $[31,78]$ in a mixed infection context, when this drug was used alone or in combination to treat $P$. falciparum malaria. Accordingly, P. vivax resistance to MQ has been reported in the Brazilian Amazon region $[16,55,79]$. In P. falciparum, resistance to MQ has been associated with increased copy number of pfmdr1 [27]. The mechanisms of MQ resistance seem to be similar between $P$. vivax and $P$. falciparum. In areas of Southeast Asia with intense and sustained MQ pressure, gene amplifications of $p v m d r 1$ were significantly more common than in those patients from other localities where there had been less parasite exposure to MQ [31]. Additionally, Suwanarusk et al. reported amplification of $21 \%$ in the pvmdr1 gene in $P$. vivax isolates from Thailand, which was associated with a twofold increase in MQ $\mathrm{IC}_{50}$ [32]. Mefloquine and CQ seem to exert selection pressure in opposite direction on pvmdr1, with gene amplification associated with an increase of susceptibility to CQ [32]. Therefore, the observed pattern of pvmdr1 copy number variation in the Brazilian Amazon region and elsewhere would be the result of pressure exerted by the two drugs. For Brazilian samples, an increase in the prevalence of $p v m d r 1$ amplification was observed over the 7-years period analysed. However, this finding requires further investigation as it might indicate that the $P$. vivax population is undergoing an increased susceptibility to CQ.

\section{Copy number variation in Plasmodium spp.: a systematic review of the literature}

A total of 309 articles were selected from four databases (PubMed, Malaria Journal, Science Direct and CAPES), and 82 of these were included in the systematic review according to the established criteria. The data of articles included in this study are available in supplementary material (Additional file 4). Studies from four continents constituted the review, where Asia and Africa were the regions with the majority of selected articles (88\%). The majority of the studies were about $P$. falciparum, related to copy number variation in $p f m d r 1$. Only two studies analysed the $p f g c h 1$ gene. For the $p v m d r 1$ gene, eight studies were eligible for inclusion. 
The distribution of resistant isolates to anti-malarials is different between the endemic regions of the world, as well as the profile of $\mathrm{CNV}$ in genes of the parasite. In the Americas and Africa, the amplification of $p f m d r 1$ is not common and is restricted to certain localities. Thus, the majority of the studies in the Americas reported an absence of $p f m d r 1$ amplification in $P$. falciparum isolates; the amplification rates varied from 6 to $38 \%$ (Fig. 2; Additional file 4) [43, 69, 80-83]. For some countries such as Brazil and French Guiana, there was approximately $30 \%$ pfmdr 1 amplification (between 2 and 4 copies) in the samples analysed. In contrast, in Africa, the prevalence of isolates carrying one copy of $p f m d r 1$ reached almost $100 \%$ in different countries, with the exception of Ethiopia (Fig. 2). Unlike these regions, Asian countries present a high rate and distribution of isolates with $p f m d r 1$ amplification (Fig. 2). The studies show that on the Thailand-Myanmar border, the amplification rate is greater, reaching $100 \%$ [84, 85]. In general, Southeast Asian countries had a greater prevalence of $P$. falciparum isolates with pfmdr1 amplification, while isolates from Southwest Asia showed no gene amplification [86-90]. Taken together, these differences in gene amplification rates may be the result of the adoption of different treatment regimens for malaria by different countries over the years. In fact, there is evidence that amplification of the $p f m d r 1$ gene in $P$. falciparum has arisen as multiple independent events, suggesting that this region of the genome is under strong selective pressure [91]. Since gene amplification has a cost to the parasite's fitness [25, 92], the drug pressure withdrawal could also have favored parasites without gene amplification contributing to the genetic variability observed.

Regarding pfgch1, only two studies evaluated the profile of CNV in field isolates. In Africa, Kiwuwa et al. have not detected any amplification in the 21 isolates analysed [93]. However, in Southeast Asia a significant difference in the rates of $p f g c h 1$ amplification was reported for isolates from Thailand (72\%) and Laos (2\%), countries that have contrasting selection histories with antifolate drugs [28]. Whereas SP was not extensively used in Laos until 2006, despite their use as official second line treatment for malaria [94], Thailand has had a longstanding history of antifolate use [95]. This geographical differentiation on pfgch1 CNV suggests local adaptations to drug pressure, which has been experimentally corroborated [53].

As described for $P$. falciparum, there is a difference regarding the distribution of $\mathrm{CNV}$ allelic frequencies of $P$. vivax isolates in the endemic areas. In the Americas and Africa, only a few studies have assessed pvmdr1 CNV, finding very low rates of amplification (1-3\%) (Fig. 3) [72, $74,83,96]$. Conversely, a higher rate (up to $59 \%$ ) of isolates harboring multiple copies of $p v m d r 1$ was reported in French Guiana, where MQ was widely used alone or in combination with artesunate for treatment of uncomplicated $P$. falciparum malaria, and therefore $P$. vivax were subjected to indirect selection pressure by the drug [73, 74]. In Asia, pvmdr1 amplification was reported in Cambodia (4 to 33\%) [37, 74] and in Thailand (7-39\%) [37, 97]. Commonly, in these areas where $p v m d r 1$ amplification is frequent, there has been intense current or past use of mefloquine to treat uncomplicated $P$. falciparum malaria $[37,74]$.

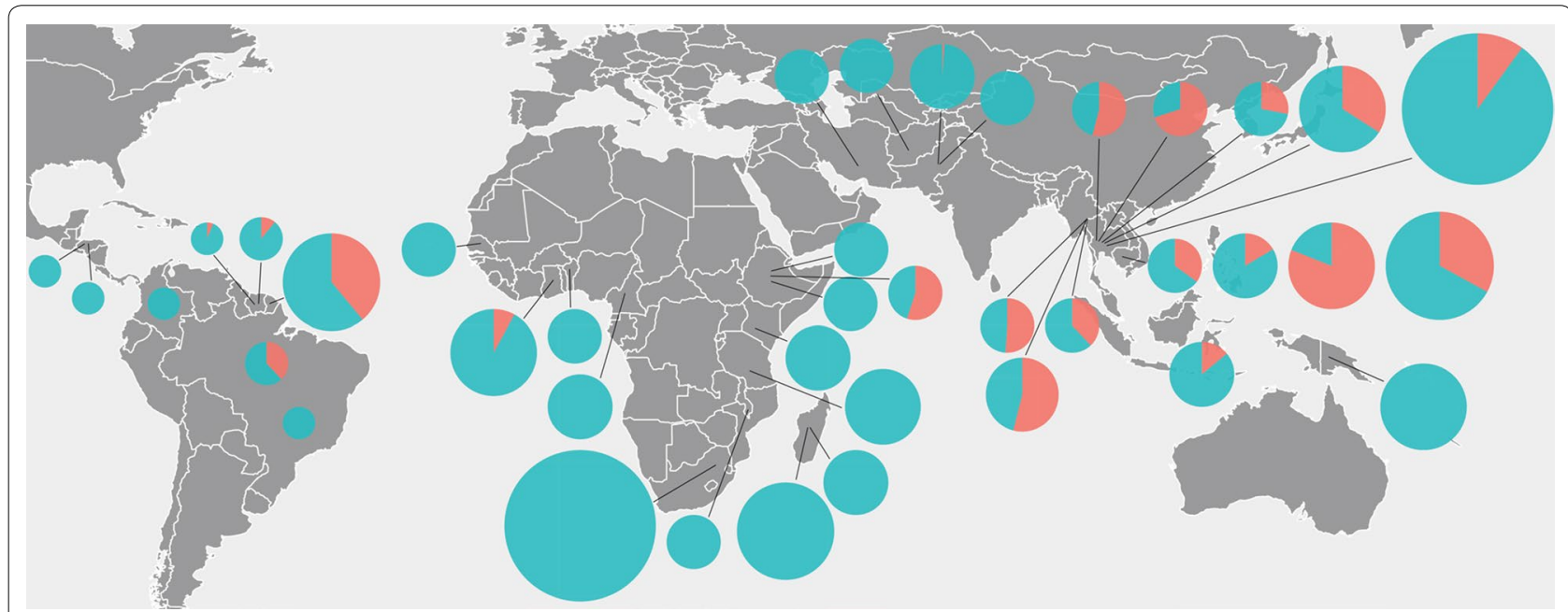

Fig. 2 Global pattern of $m d r 1$ copy number variation in P. falciparum isolates. The frequency of isolates carrying one or multiple copies of pfmdr 1 is indicated by green and red pie charts, respectively. Only the studies that analysed more than 100 isolates are shown in the map. The size of the pie charts is proportional to the number of isolates analysed in each study 


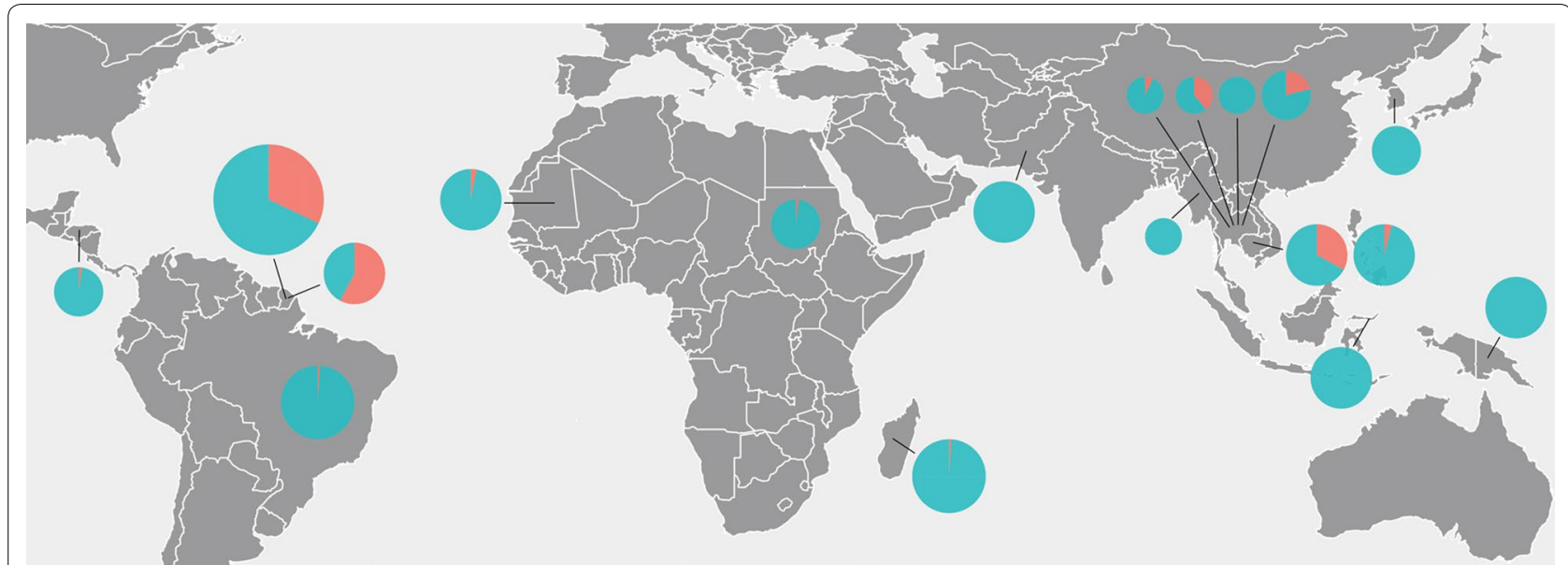

Fig. 3 Global pattern of $m d r 1$ copy number variation in P. vivax isolates. The frequency of isolates carrying one or multiple copies of $p v m d r 1$ is indicated by green and red pie charts, respectively. The size of the pie charts is proportional to the number of isolates analysed in each study

\section{Conclusion}

For P. falciparum isolates, no amplification was found for pfmdr1 or pfgch1, but the SNP K76T associated with chloroquine resistance was present. Notably, the rate of $p v m d r 1$ amplification observed in this study was significantly higher than previously reported for isolates circulating in Northern Brazil. Furthermore, a wide variation in the amplification rate of pvmdrl was observed between the two study sites in Brazil. In a global view, in the Americas and Africa the amplification rates of the $m d r 1$ gene of $P$. falciparum were generally very low, with a few exceptions. In Asia, particularly in Thailand and Cambodia, the highest rates of pfmdr1 amplification were reported. In general, P. falciparum showed the highest rates of gene amplification; however, it is important to highlight that especially for $P$. vivax, the available information is restricted and may not reflect the actual picture of genetic variability for this species.

\section{Additional files}

Additional file 1. Accuracy of quantitative Real-Time PCR assay to estimate the copy number variation in genes of Plasmodium falciparum and Plasmodium vivax.

Additional file 2. Article selection by preestablished criteria.

Additional file 3. Real-time PCR estimates of the relative copy number of P. falciparum (A and B) and P. vivax genes (C). Collection site of isolates is indicated on the $x$-axis. Only samples with a minimum relative quantification above 1.5 were considered amplified. RO, Rondônia.

Additional file 4. Systematic review result for copy number variation in genes related to drug resistance in Plasmodium vivax and Plasmodium falciparum isolates worldwide.

\section{Abbreviations}

SNP: single nucleotide polymorphism; CNV: copy number variation; $\mathrm{mdr}$ : multidrug resistance gene-1; P-gh1: P-glycoprotein homolog 1; gch1: GTP cyclohydrolase 1; crt: chloroquine-resistant transporter; dhfr: dihydrofolate reductase; dhps: dihydropteroate synthetase; PCR-RFLP: polymerase chain reaction followed by restriction fragment length polymorphism; $Q P C R$ : quantitative polymerase chain reaction; $C Q$ : chloroquine; QN: quinine; SP: sulphadoxine-pyrimethamine; ACT: artemisin-based combination therapy; MQ: mefloquine; PQ: primaquine; $\mathrm{HF}$ : halofantrine; ATP: adenosine triphosphate; $\mathrm{IC}_{50}$ : half maximal inhibitory concentration.

\section{Authors' contributions}

TNS and CFAB designed the study. TNS, GLC and LCA performed the experiments and analysed the data. CFAB, LHC and CJFF contributed reagents/materials/analysis tools. TNS, CFAB, LHC and GLC wrote the manuscript. All authors read and approved the final manuscript.

\section{Author details}

${ }^{1}$ Molecular Biology and Malaria Immunology Research Group, Centro de Pesquisas René Rachou, Fundação Oswaldo Cruz (FIOCRUZ), Belo Horizonte, Minas Gerais, Brazil. ${ }^{2}$ Hospital Julio Muller, Universidade Federal de Mato Grosso, Cuiabá, Mato Grosso, Brazil.

\section{Acknowledgements}

We are grateful to all the patients who made this study possible. We also thank Dr. Rubens Lima do Monte Neto to help build maps. We thank the Programme for Technological Development in Tools for Health-PDTIS platform (FIOCRUZ) for Real-time PCR facilities. CJF, LHC and CAB thank CNPq for the research scholarship support. GLC thanks CAPES (Coordination of Superior Level Staff Improvement) for scholarship support and the Graduate Programme in Health Sciences of CPqRR.

\section{Competing interests}

The authors declare that they have no competing interests.

\section{Availability of data and materials}

The datasets used and/or analysed during the current study are available from the corresponding author on reasonable request.

\section{Ethical approval}

Ethical approval for the study was obtained from the Ethics and Research Committee of René Rachou Research Center (Protocol Number 377.205). All participants signed a written informed consent, including the next of kin, caretakers, or guardians on behalf of the minors/children enrolled in the study.

\section{Funding}

This study has financial support from FAPEMIG (Fundação de Amparo à Pesquisa do estado de Minas Gerais) and CNPq (National Council for Scientific and Technological Development). 


\section{Publisher's Note}

Springer Nature remains neutral with regard to jurisdictional claims in published maps and institutional affiliations.

Received: 15 June 2016 Accepted: 7 April 2017 Published online: 19 April 2017

\section{References}

1. WHO. World Malaria Report 2015. Geneva: World Health Organization; 2015.

2. SVS. Malária: Monitoramento dos casos no Brasil em 2014. (Saúde SdVeSMd ed., vol. 462015.

3. WHO. Guidelines for the treatment of malaria, 3nd edition. Geneva: World Health Organization; 2015.

4. Neiva A. Formação de raça do hematozoário do impaludismo rezistente à quinina. Mem Inst Oswaldo Cruz. 1910;2:131-40.

5. Hyde JE. Drug-resistant malaria. Trends Parasitol. 2005;21:494-8

6. Gama BE, Lacerda MV, Daniel-Ribeiro CT, Ferreira-da-Cruz Mde F. Chemoresistance of Plasmodium falciparum and Plasmodium vivax parasites in Brazil: consequences on disease morbidity and control. Mem Inst Oswaldo Cruz. 2011;106:159-66.

7. Almeida Netto J, Oliveira G, Sampaio J. Resistência do Plasmodium falciparum à associação sulfamídicos-antifolínicos na região CentroOeste do Brasil. Dados referentes ao estudo de 104 casos. Rev Pat Trop. 1972;1:385-93.

8. Noedl H, Se Y, Schaecher K, Smith BL, Socheat D, Fukuda MM. Evidence of artemisinin-resistant malaria in western Cambodia. N Engl J Med. 2008;359:2619-20.

9. Dondorp AM, Nosten F, Yi P, Das D, Phyo AP, Tarning J, et al. Artemisinin resistance in Plasmodium falciparum malaria. N Engl J Med. 2009;361:455-67.

10. Phyo AP, Nkhoma S, Stepniewska K, Ashley EA, Nair S, McGready R, et al. Emergence of artemisinin-resistant malaria on the western border of Thailand: a longitudinal study. Lancet. 2012;379:1960-6.

11. Ashley EA, Dhorda M, Fairhurst RM, Amaratunga C, Lim P, Suon S, et al. Spread of artemisinin resistance in Plasmodium falciparum malaria. N Engl J Med. 2014;371:411-23.

12. Vreden SG, Jitan JK, Bansie RD, Adhin MR. Evidence of an increased incidence of day 3 parasitaemia in Suriname: an indicator of the emerging resistance of Plasmodium falciparum to artemether. Mem Inst Oswaldo Cruz. 2013:108:968-73.

13. Oliveira-Ferreira J, Lacerda MV, Brasil P, Ladislau JL, Tauil PL, Daniel-Ribeiro CT. Malaria in Brazil: an overview. Malar J. 2010:9:115.

14. Alecrim MdG. Alecrim W, Macedo V. Plasmodium vivax resistance to chloroquine (R2) and mefloquine (R3) in Brazilian Amazon region. Rev Soc Bras Med Trop. 1999;32:67-8.

15. de Santana Filho FS, Arcanjo AR, Chehuan YM, Costa MR, Martinez-Espinosa FE, Vieira JL, et al. Chloroquine-resistant Plasmodium vivax, Brazilian Amazon. Emerg Infect Dis. 2007;13:1125-6.

16. Chehuan YF, Costa MR, Costa JS, Alecrim MG, Nogueira F, Silveira H, et al In vitro chloroquine resistance for Plasmodium vivax isolates from the Western Brazilian Amazon. Malar J. 2013;12:226.

17. Marques MM, Costa MR, Santana Filho FS, Vieira JL, Nascimento MT, Brasil $\mathrm{LW}$, et al. Plasmodium vivax chloroquine resistance and anemia in the western Brazilian Amazon. Antimicrob Agents Chemother. 2014;58:342-7.

18. Alexandre MA, Ferreira CO, Siqueira AM, Magalhães BL, Mourão MP, Lacerda MV, et al. Severe Plasmodium vivax malaria, Brazilian Amazon. Emerg Infect Dis. 2010;16:1611-4.

19. Lacerda MV, Fragoso SC, Alecrim MG, Alexandre MA, Magalhaes BM, Siqueira AM, et al. Postmortem characterization of patients with clinical diagnosis of Plasmodium vivax malaria: to what extent does this parasite kill? Clin Infect Dis. 2012;55:67-74.

20. Goncalves LA, Cravo P, Ferreira MU. Emerging Plasmodium vivax resistance to chloroquine in South America: an overview. Mem Inst Oswaldo Cruz. 2014:109:534-9.

21. Duraisingh MT, Cowman AF. Contribution of the $p f m d r 1$ gene to antimalarial drug-resistance. Acta Trop. 2005;94:181-90.
22. Cooper GM, Nickerson DA, Eichler EE. Mutational and selective effects on copy-number variants in the human genome. Nat Genet. 2007;39:22-9.

23. Freeman JL, Perry GH, Feuk L, Redon R, McCarroll SA, Altshuler DM, et al. Copy number variation: new insights in genome diversity. Genome Res. 2006;16:949-61.

24. Anderson TJ, Patel J, Ferdig MT. Gene copy number and malaria biology. Trends Parasitol. 2009;25:336-43.

25. Preechapornkul P, Imwong M, Chotivanich K, Pongtavornpinyo W, Dondorp AM, Day NP, et al. Plasmodium falciparum pfmdr1 amplification, mefloquine resistance, and parasite fitness. Antimicrob Agents Chemother. 2009:53:1509-15.

26. Cowman AF, Galatis D, Thompson JK. Selection for mefloquine resistance in Plasmodium falciparum is linked to amplification of the pfmdrl gene and cross-resistance to halofantrine and quinine. Proc Natl Acad Sci USA. 1994;91:1143-7.

27. Price RN, Uhlemann AC, Brockman A, McGready R, Ashley E, Phaipun $\mathrm{L}$, et al. Mefloquine resistance in Plasmodium falciparum and increased pfmdr1 gene copy number. Lancet. 2004;364:438-47.

28. Nair S, Miller B, Barends M, Jaidee A, Patel J, Mayxay M, et al. Adaptive copy number evolution in malaria parasites. PLoS Genet. 2008;4:1000243.

29. Ribacke U, Mok BW, Wirta V, Normark J, Lundeberg J, Kironde F, et al. Genome wide gene amplifications and deletions in Plasmodium falciparum. Mol Biochem Parasitol. 2007;155:33-44.

30. Kidgell C, Volkman SK, Daily J, Borevitz JO, Plouffe D, Zhou Y, et al. A systematic map of genetic variation in Plasmodium falciparum. PLoS Pathog. 2006;2:e57.

31. Imwong M, Pukrittayakamee S, Pongtavornpinyo W, Nakeesathit S, Nair S, Newton P, Nosten F, et al. Gene amplification of the multidrug resistance 1 gene of Plasmodium vivax isolates from Thailand, Laos, and Myanmar. Antimicrob Agents Chemother. 2008;52:2657-9.

32. Suwanarusk R, Chavchich M, Russell B, Jaidee A, Chalfein F, Barends M, et al. Amplification of pvmdr1 associated with multidrug-resistant Plasmodium vivax. J Infect Dis. 2008:198:1558-64.

33. Sidhu AB, Verdier-Pinard D, Fidock DA. Chloroquine resistance in Plasmodium falciparum malaria parasites conferred by pfcrt mutations. Science. 2002;298:210-3.

34. Wellems TE, Plowe CV. Chloroquine-resistant malaria. J Infect Dis. 2001;184:770-6.

35. Suwanarusk R, Russell B, Chavchich M, Chalfein F, Kenangalem E, Kosaisavee $\mathrm{V}$, et al. Chloroquine resistant Plasmodium vivax: in vitro characterisation and association with molecular polymorphisms. PLOS ONE. 2007;2:e1089.

36. Marfurt J, de Monbrison F, Brega S, Barbollat L, Muller I, Sie A, et al. Molecular markers of in vivo Plasmodium vivax resistance to amodiaquine plus sulfadoxine-pyrimethamine: mutations in pvdhfr and pvmdr1. J Infect Dis. 2008;198:409-17.

37. Lin JT, Patel JC, Kharabora O, Sattabongkot J, Muth S, Ubalee R, et al. Plasmodium vivax isolates from Cambodia and Thailand show high genetic complexity and distinct patterns of $P$. vivax multidrug resistance gene 1 (pvmdr1) polymorphisms. Am J Trop Med Hyg. 2013;88:1116-23.

38. Snounou G, Viriyakosol S, Zhu XP, Jarra W, Pinheiro L, do Rosario VE, et al. High sensitivity of detection of human malaria parasites by the use of nested polymerase chain reaction. Mol Biochem Parasitol. 1993;61:315-20.

39. Durand R, Huart V, Jafari S, Le Bras J. Rapid detection of a molecular marker for chloroquine-resistant falciparum malaria. Antimicrob Agents Chemother. 2002;46:2684-6.

40. Lopes D, Nogueira F, Gil JP, Ferreira C, do Rosario VE, Cravo P. pfert and pfmdr 1 mutations and chloroquine resistance in Plasmodium falciparum from Sao Tome and Principe. West Africa. Ann Trop Med Parasitol. 2002:96:831-4.

41. Reed MB, Saliba KJ, Caruana SR, Kirk K, Cowman AF. Pgh1 modulates sensitivity and resistance to multiple antimalarials in Plasmodium falciparum. Nature. 2000:403:906-9.

42. Peel SA, Bright P, Yount B, Handy J, Baric RS. A strong association between mefloquine and halofantrine resistance and amplification, overexpression, and mutation in the P-glycoprotein gene homolog ( $p f m d r)$ of Plasmodium falciparum in vitro. Am J Trop Med Hyg. 1994;51:648-58.

43. Inoue J, Lopes D, do Rosario V, Machado M, Hristov AD, Lima GF, et al. Analysis of polymorphisms in Plasmodium falciparum genes related to 
drug resistance: a survey over four decades under different treatment policies in Brazil. Malar J. 2014;13:372.

44. Machado R, Povoa M, Calvosa V, Ferreira M, Rossit A, dos Santos E, et al. Genetic structure of Plasmodium falciparum populations in the Brazilian Amazon region. J Infect Dis. 2004;190:1547-55.

45. Duah NO, Matrevi SA, de Souza DK, Binnah DD, Tamakloe MM, Opoku VS, et al. Increased pfmdr1 gene copy number and the decline in pfcrt and pfmdr1 resistance alleles in Ghanaian Plasmodium falciparum isolates after the change of anti-malarial drug treatment policy. Malar J. 2013;12:377.

46. Ngalah BS, Ingasia LA, Cheruiyot AC, Chebon L, Juma DW, Muiruri P, et al. Analysis of major genome loci underlying artemisinin resistance and pfmdr 1 copy number in pre- and post-ACTs in western Kenya. Sci Rep. 2015:5:8308.

47. Wootton JC, Feng X, Ferdig MT, Cooper RA, Mu J, Baruch DI, et al. Genetic diversity and chloroquine selective sweeps in Plasmodium falciparum. Nature. 2002:418:320-3.

48. Reece SE, Ramiro RS, Nussey DH. Plastic parasites: sophisticated strategies for survival and reproduction? Evol Appl. 2009;2:11-23.

49. Mideo N, Reece SE. Plasticity in parasite phenotypes: evolutionary and ecological implications for disease. Future Microbiol. 2012;7:17-24.

50. Hoffmann U, Kroemer HK. The ABC transporters MDR1 and MRP2: multiple functions in disposition of xenobiotics and drug resistance. Drug Metab Rev. 2004;36:669-701.

51. Peterson DS, Walliker D, Wellems TE. Evidence that a point mutation in dihydrofolate reductase-thymidylate synthase confers resistance to pyrimethamine in falciparum malaria. Proc Natl Acad Sci USA. 1988;85:9114-8.

52. Triglia T, Menting JG, Wilson C, Cowman AF. Mutations in dihydropteroate synthase are responsible for sulfone and sulfonamide resistance in Plasmodium falciparum. Proc Natl Acad Sci USA. 1997;94:13944-9.

53. Heinberg A, Siu E, Stern C, Lawrence EA, Ferdig MT, Deitsch KW, et al. Direct evidence for the adaptive role of copy number variation on antifolate susceptibility in Plasmodium falciparum. Mol Microbiol. 2013;88:702-12.

54. Kumpornsin K, Modchang C, Heinberg A, Ekland EH, Jirawatcharadech P, Chobson $\mathrm{P}$, et al. Origin of robustness in generating drug-resistant malaria parasites. Mol Biol Evol. 2014;31:1649-60.

55. Aguiar AC, Pereira DB, Amaral NS, De Marco L, Krettli AU. Plasmodium vivax and Plasmodium falciparum ex vivo susceptibility to anti-malarials and gene characterization in Rondonia, West Amazon, Brazil. Malar. J. 2014;13:73.

56. Gbotosho GO, Folarin OA, Bustamante C, da Silva LH, Mesquita E, Sowunmi A, et al. Different patterns of pfcrt and pfmdr1 polymorphisms in P. falciparum isolates from Nigeria and Brazil: the potential role of antimalarial drug selection pressure. Am J Trop Med Hyg. 2012;86:211-3.

57. Boulos M, Dutra AP, DiSanti SM, Shiroma M, Amato Neto V. The clinical evaluation of quinine for the treatment of Plasmodium falciparum malaria. Rev Soc Bras Med Trop. 1997;30:211-3.

58. Durrand V, Berry A, Sem R, Glaziou P, Beaudou J, Fandeur T. Variations in the sequence and expression of the Plasmodium falciparum chloroquine resistance transporter ( $P f C r t)$ and their relationship to chloroquine resistance in vitro. Mol Biochem Parasitol. 2004;136:273-85.

59. Durand R, Jafari S, Vauzelle J, Delabre JF, Jesic Z, Le Bras J. Analysis of pfcrt point mutations and chloroquine susceptibility in isolates of Plasmodium falciparum. Mol Biochem Parasitol. 2001;114:95-102.

60. Mockenhaupt FP, Ehrhardt S, Eggelte TA, Agana-Nsiire P, Stollberg K, Mathieu A, et al. Chloroquine-treatment failure in northern Ghana: roles of pfcrt T76 and pfmdr1 Y86. Ann Trop Med Parasitol. 2005;99:723-32.

61. Picot S, Olliaro P, de Monbrison F, Bienvenu AL, Price RN, Ringwald P. A systematic review and meta-analysis of evidence for correlation between molecular markers of parasite resistance and treatment outcome in falciparum malaria. Malar J. 2009;8:89.

62. Veiga MI, Dhingra SK, Henrich PP, Straimer J, Gnadig N, Uhlemann AC, et al. Globally prevalent PfMDR1 mutations modulate Plasmodium falciparum susceptibility to artemisinin-based combination therapies. Nat Commun. 2016;7:11553.

63. Bustamante C, Folarin OA, Gbotosho GO, Batista CN, Mesquita EA, Brindeiro RM, et al. In vitro-reduced susceptibility to artemether in $P$. falciparum and its association with polymorphisms on transporter genes. J Infect Dis. 2012;206:324-32.
64. Duraisingh MT, Roper C, Walliker D, Warhurst DC. Increased sensitivity to the antimalarials mefloquine and artemisinin is conferred by mutations in the pfmdr1 gene of Plasmodium falciparum. Mol Microbiol. 2000;36:955-61.

65. Lobo E, de Sousa B, Rosa S, Figueiredo P, Lobo L, Pateira S, et al. Prevalence of $\mathrm{pfm} d r 1$ alleles associated with artemether-lumefantrine tolerance/resistance in Maputo before and after the implementation of artemisinin-based combination therapy. Malar J. 2014;13:300.

66. Pickard AL, Wongsrichanalai C, Purfield A, Kamwendo D, Emery K, Zalewski C, et al. Resistance to antimalarials in Southeast Asia and genetic polymorphisms in pfmdr1. Antimicrob Agents Chemother. 2003:47:2418-23.

67. Duraisingh MT, Jones P, Sambou I, von Seidlein L, Pinder M, Warhurst DC. The tyrosine-86 allele of the pfmdr 1 gene of Plasmodium falciparum is associated with increased sensitivity to the anti-malarials mefloquine and artemisinin. Mol Biochem Parasitol. 2000;108:13-23.

68. Griffing S, Syphard L, Sridaran S, McCollum AM, Mixson-Hayden T, Vinayak $S$, et al. pfmdr1 amplification and fixation of pfcrt chloroquine resistance alleles in Plasmodium falciparum in Venezuela. Antimicrob Agents Chemother. 2010;54:1572-9.

69. Adhin MR, Labadie-Bracho M, Bretas G. Molecular surveillance as monitoring tool for drug-resistant Plasmodium falciparum in Suriname. Am J Trop Med Hyg. 2013;89:311-6.

70. Bacon DJ, McCollum AM, Griffing SM, Salas C, Soberon V, Santolalla M, et al. Dynamics of malaria drug resistance patterns in the Amazon basin region following changes in Peruvian national treatment policy for uncomplicated malaria. Antimicrob Agents Chemother. 2009;53:2042-51.

71. WHO. World Malaria Report 2013. Geneva: World Health Organization; 2013.

72. Vargas-Rodriguez Rdel C, da Silva Bastos M, Menezes MJ, Orjuela-Sanchez P, Ferreira MU. Single-nucleotide polymorphism and copy number variation of the multidrug resistance-1 locus of Plasmodium vivax: local and global patterns. Am J Trop Med Hyg. 2012;87:813-21.

73. Faway E, Musset L, Pelleau S, Volney B, Casteras J, Caro V, et al. Plasmodium vivax multidrug resistance-1 gene polymorphism in French Guiana. Malar J. 2016;15:540.

74. Khim N, Andrianaranjaka V, Popovici J, Kim S, Ratsimbasoa A, Benedet C, et al. Effects of mefloquine use on Plasmodium vivax multidrug resistance. Emerg Infect Dis. 2014;20:1637-44.

75. ter Kuile FO, Luxemburger C, Nosten F, Thwai KL, Chongsuphajaisiddhi T, White NJ. Predictors of mefloquine treatment failure: a prospective study of 1590 patients with uncomplicated falciparum malaria. Trans R Soc Trop Med Hyg. 1995;89:660-4.

76. Price RN, Nosten F, Luxemburger C, van Vugt M, Phaipun L, Chongsuphajaisiddhi T, et al. Artesunate/mefloquine treatment of multi-drug resistant falciparum malaria. Trans R Soc Trop Med Hyg. 1997;91:574-7.

77. Silvino AC, Costa GL, Araujo FC, Ascher DB, Pires DE, Fontes CJ, et al. Variation in human cytochrome P-450 drug-metabolism genes: a gateway to the understanding of Plasmodium vivax relapses. PLOS ONE. 2016;11:e0160172.

78. Snounou G, White NJ. The co-existence of Plasmodium: sidelights from falciparum and vivax malaria in Thailand. Trends Parasitol. 2004;20:333-9.

79. Pratt-Riccio LR, Chehuan YF, Siqueira MJ, das Gracas Alecrim M, BiancoJunior C, Druilhe P, et al. Use of a colorimetric (DELI) test for the evaluation of chemoresistance of Plasmodium falciparum and Plasmodium vivax to commonly used anti-plasmodial drugs in the Brazilian Amazon. Malar J. 2013;12:281.

80. Zalis MG, Pang L, Silveira MS, Milhous WK, Wirth DF. Characterization of Plasmodium falciparum isolated from the Amazon region of Brazil: evidence for quinine resistance. Am J Trop Med Hyg. 1998;58:630-7.

81. Legrand E, Yrinesi J, Ekala MT, Peneau J, Volney B, Berger F, et al. Discordant temporal evolution of Pfcrt and Pfmdr1 genotypes and Plasmodium falciparum in vitro drug susceptibility to 4 -aminoquinolines after drug policy change in French Guiana. Antimicrob Agents Chemother. 2012;56:1382-9.

82. Labadie-Bracho M, Adhin MR. Increased pfmdr1 copy number in Plasmodium falciparum isolates from Suriname. Trop Med Int Health. 2013;18:796-9.

83. Jovel IT, Mejia RE, Banegas E, Piedade R, Alger J, Fontecha G, et al. Drug resistance associated genetic polymorphisms in Plasmodium falciparum and Plasmodium vivax collected in Honduras, Central America. Malar J. 2011;10:376. 
84. Setthaudom C, Tan-ariya P, Sitthichot N, Khositnithikul R, Suwandittakul N, Leelayoova S, et al. Role of Plasmodium falciparum chloroquine resistance transporter and multidrug resistance 1 genes on in vitro chloroquine resistance in isolates of Plasmodium falciparum from Thailand. Am J Trop Med Hyg. 2011;85:606-11.

85. Poyomtip T, Suwandittakul N, Sitthichot N, Khositnithikul R, Tan-ariya P, Mungthin M. Polymorphisms of the pfmdr1 but not the pfnhe-1 gene is associated with in vitro quinine sensitivity in Thai isolates of Plasmodium falciparum. Malar J. 2012;11:7.

86. Khattak AA, Venkatesan M, Jacob CG, Artimovich EM, Nadeem MF, Nighat $F$, et al. A comprehensive survey of polymorphisms conferring anti-malarial resistance in Plasmodium falciparum across Pakistan. Malar J. 2013;12:300.

87. Basco LK, de Pecoulas PE, Le Bras J, Wilson CM. Plasmodium falciparum: molecular characterization of multidrug-resistant Cambodian isolates. Exp Parasitol. 1996;82:97-103.

88. Awab GR, Pukrittayakamee S, Jamornthanyawat N, Yamin F, Dondorp AM, Day NP, et al. Prevalence of antifolate resistance mutations in Plasmodium falciparum isolates in Afghanistan. Malar J. 2013;12:96.

89. Pirahmadi S, Zakeri S, Afsharpad M, Djadid ND. Mutation analysis in pfmdr 1 and pfmrp 1 as potential candidate genes for artemisinin resistance in Plasmodium falciparum clinical isolates 4 years after implementation of artemisinin combination therapy in Iran. Infect Genet Evol. 2013;14:327-34.

90. Jovel IT, Ferreira PE, Veiga MI, Malmberg M, Mårtensson A, Kaneko A, et al. Single nucleotide polymorphisms in Plasmodium falciparum $\mathrm{V}$ type $\mathrm{H}$
(+) pyrophosphatase gene (pfvp2) and their associations with pfcrt and pfmdr1 polymorphisms. Infect Genet Evol. 2014;24:111-5.

91. Triglia T, Foote SJ, Kemp DJ, Cowman AF. Amplification of the multidrug resistance gene pfmdr 1 in Plasmodium falciparum has arisen as multiple independent events. Mol Cell Biol. 1991;11:5244-50.

92. Rosenthal PJ. The interplay between drug resistance and fitness in malaria parasites. Mol Microbiol. 2013;89:1025-38.

93. Kiwuwa MS, Byarugaba J, Wahlgren M, Kironde F. Detection of copy number variation and single nucleotide polymorphisms in genes involved in drug resistance and other phenotypic traits in P. falciparum clinical isolates collected from Uganda. Acta Trop. 2013;125:269-75.

94. Mayxay M, Pongvongsa T, Phompida S, Phetsouvanh R, White NJ, Newton PN. Diagnosis and management of malaria by rural community health providers in the Lao People's Democratic Republic (Laos). Trop Med Int Health. 2007;12:540-6.

95. Bunnag D, Harinasuta T. The current status of drug resistance in malaria. Int J Parasitol. 1987;17:169-80.

96. Lekweiry KM, Boukhary AO, Gaillard T, Wurtz N, Bogreau H, Hafid JE, Trape JF, Bouchiba H, Salem MS, Pradines B, Rogier C. Molecular surveillance of drug-resistant Plasmodium vivax using pvdhfr, pvdhps and pvmdr 1 markers in Nouakchott. Mauritania. J Antimicrob Chemother. 2012;67:367-74.

97. Lu F, Lim CS, Nam DH, Kim K, Lin K, Kim TS, et al. Genetic polymorphism in pvmdr 1 and pvcrt-o genes in relation to in vitro drug susceptibility of Plasmodium vivax isolates from malaria-endemic countries. Acta Trop. 2011;117:69-75.

\section{Submit your next manuscript to BioMed Central and we will help you at every step:}

- We accept pre-submission inquiries

- Our selector tool helps you to find the most relevant journal

- We provide round the clock customer support

- Convenient online submission

- Thorough peer review

- Inclusion in PubMed and all major indexing services

- Maximum visibility for your research

Submit your manuscript at www.biomedcentral.com/submit
() Biomed Central 